\title{
National Qualification Systems Integration using Ontologies
}

\author{
Claudio Cubillos ${ }^{1}$, Fabrizio Lamberti ${ }^{2}$ and Claudio Demartini ${ }^{2}$ \\ 1 Escuela de Ingeniería Informática, Pontificia Universidad Católica de \\ Valparaíso, Av. Brazil 2241, Valparaíso, Chile \\ claudio.cubillos@ucv.cl \\ 2 Dipartimento di Automatica e Informatica, Politecnico di Torino \\ Cso. Duca degli Abruzzi 24, I-10129, Torino, Italia \\ \{fabrizio.lamberti,claudio.demartini\}@polito.it
}

\begin{abstract}
This work presents the use of ontologies as a way to tackle the problem of integration of qualification systems in order to enable the transparency and mobility of students at European level. For this, qualification systems at post-secondary non-academic levels of nine EU countries have been formalized in terms of profile, activities, competences, learning outcomes, etc., first using UML for a human-readable model and then using OWL for a machine-processable one. In addition, concrete qualification profiles have been used as a case study to check the models' correctness.
\end{abstract}

\section{Introduction}

The transparency of qualifications and mobility of students among countries has turned out to be a relevant topic in recent years, especially in the European context. In fact the European Union has several initiatives in this sense: the program Socrates--Erasmus and European Credit Transfer System (E.C.T.S) [6], plus a set of laws and treaties devoted to the promotion of the equity with the increase of education and training in order to make, no later than 2010, the European Society of Knowledge become the most competitive in the world.

For its success, first it should be investigated how transparency, comparability, transferability and recognition of competences and/or qualifications can be carried out between different countries and at different levels. In order to enable this transparency in terms of competency recognition, it is required first to provide integration among the underlying information systems that manage the information on each school, organization and country.

Please use the following format when citing this chapter:

Cubillos, C., Lamberti, F., Demartini, C., 2006, in Intemational Federation for Information Processing, Volume 210, Education for the $21^{\text {st }}$ Century-Impact of ICT and Digital Resources, eds. D. Kumar, and Turner J., (Boston: Springer), pp. 285-289. 
There exists a semantic heterogeneity problem across the different national qualification systems. The connection capable of actually guaranteeing the transparency and mobility of professional qualifications strictly relies on the availability of a formal representation of the underlying models and their structure in terms of competences, formative units, learning outcomes, etc. This would allow the promotion of mutual understanding of these systems at EU level, the possibility to make comparisons and establish analogies among their concepts, and finally to enable the interoperation of such national systems.

The main scope of this work is the use of ontologies to provide Common Access to the Information regarding the qualification systems of nine European countries, namely France, Germany, Greece, Ireland, Italy, Netherlands, Romania, Slovakia and Spain. The considered systems regard the Vocational Education and Training (VET) area at the post-secondary non-academic level.

\subsection{The Maastricht Treaty}

The VET process, known as the Bruges-Copenhagen process (Copenhagen Declaration of 2002 [1]), refers to the Maastricht Treaty. The process of BrugesCopenhagen foresees the increase of education and training in order to promote the European Society of Knowledge. A significant starting point is represented by the following declaration, born inside a debate of the technical group for credit transfer. "Investigating how transparency, comparability, transferability and recognition of competences and/or qualifications, between different countries and at different levels, could be promoted by developing reference levels, common principles for certification, and common measures, including a credit transfer system for vocational education and training".

The citizen student's mobility is now done mostly in higher education (H.E.), while in vocational educational training (VET) it is more a declaration of intents than a praxis. The VET student has enjoyed support for mobility just in the specific case of the internship abroad, while during the transit among educational institutions (especially for what concerns acceptance to a University) rules for the equipollence of qualifications are applied (Convention of Paris - 11 December 1953 [7]). European Universities, for what concerns the European program Socrates - Erasmus, faced the problem and found a possible solution by building an instrument that can be functional for that goal: a credit system called European Credit Transfer System (E.C.T.S). The efficacy of this system is demonstrated by its widespread application that, since 1997, has involved a large number of students and more than 1.200 European academic organizations, becoming an important point for the innovation of didactics in European university education, which is still very nonhomogeneous.

The necessity of building a similar system for VET led to the definition of the European Credit System for VET (E.C.V.E.T.)[8], which is able to support students' and workers' mobility. It is a first step towards learners' mobility, but still not enough as it only enables recognition in terms of workload and courses taken abroad by students but does not explain how these foreign courses fit in the local national system and whether they map (partially or totally) to the national professional profiles and their programmes in order to recognize the equipollences. Therefore, 
technologies that truly enable the integration of VET systems at a more fine-grained level (e.g., in terms of objectives, competences, content) are required.

\subsection{Ontologies as a way for providing interoperation}

According to Gruber, ontology can be defined as " $A$ Formal Explicit Specification of a Shared Conceptualization" [2]. It is a new tool intended more as a new way of modelling rather than a new technology, but that can provide unexpected possibilities of applications, in terms of integration and inter-operation. In our case the specific benefits from ontology use are: 1) Sharing common understanding of the qualification systems (at the VET level), their structure and information (knowledge base); 2) Enabling reuse of VET knowledge as systems evolve and need to be adaptable and easily integrable with other systems; 3) Making explicit the assumptions on each national VET system and thus making it easier for a newer person to understand them; 4) Promoting the consistency and lack of ambiguity within each national VET system; and 5) Enabling interoperability among the different systems through their formalization, allowing easy finding of similar concepts and the establishment of equivalences among their constructs.

\section{Construction methodology}

\subsection{Initial document gathering \& UML formalization}

This first step involved collecting and analyzing all the relevant information looking towards the future construction of a corresponding visual diagram model for each national VET system [3]. This involved gathering at different levels from each country:

- The national educational system. An overview of the general educational system of the country, specifying the different stages and paths that can be followed by the learner. This provides an idea on how the national VET system is positioned within the national context as a whole.

- The post-secondary non-academic education. Overview of the post-secondary non-academic system as a whole, detailing the different types of schools within this educational level. The information was required to better understand the different alternatives at this stage for then choosing a specific one.

- The post-secondary non-academic education system analyzed for the project. Detailed description of the particular VET system chosen to be modeled among the different alternatives at the post-secondary non-academic level of each country.

- The profile's constitutive parts and description of concepts. Detailed information on the professional profile and curriculum structure within the VET alternative chosen.

The Unified Modelling Language (UML) [4], a well-known formal graphical representation, was selected for the models' construction, representing all the conceptual elements identified within each VET system. It was considered crucial to 
provide a human-readable and intuitive way of model specification, as most of the partners involved in the work were not familiar with systems modelling. Thus, dedicated graphical models for France, Germany, Greece, Ireland, Italy, Netherlands, Romania, Slovakia and Spain have been designed. A full description of each of these can be obtained from [3].

\subsection{Template construction \& case study compilation}

The second step involved the construction of the proper set of forms (templates in MS-Word) for the UML models for each country. The scope in constructing this template per model was twofold; 1) to check the UML diagram's correctness through the template, especially considering that not many of the partners involved were familiar with the UML language and its formalities, and 2) to collect specific case studies (concrete vocational profiles) used to check and support the formal model's correctness (forms and UML diagrams) and to provide a common knowledge base useful for simulating interoperability and transparency of qualifications.

Therefore it was considered opportune to develop a form representing the formal model, but now in a more familiar format for all the partners. In other words, the form actually presents a tabular format of the UML diagram it corresponds to. In this way it was easy for the rest of the partners to understand the modeling and check, through the form, its correctness. Of course this activity was carried out in several iterations. The forms were referred to as knowledge base templates, and they present the same core elements identified within the UML diagrams.

The step of case study compilation could also leverage possible inconsistencies in the models not detected up to now. In fact partners could easily make their concrete profiles or curriculums (cases of study) fit in the corresponding template form and in cases of difficulties check if the inconsistency was due to a form (and therefore model) problem or was because of a study case described not following the reference documentation (official norms, decrees, etc.).

The next step was the migration of this paper-format knowledge base to a form more useful for computer programs, which is explained in the following sections.

\subsection{Ontology construction}

This step involved the construction of the ontologies using as starting point the UML models produced as a first formalization for each of the ten VET systems. By using the Ontology Web Language (OWL) as the language for describing the ontologies and the Protégé tool for carrying out this process, all the necessary conditions were met. OWL is a new language for the Semantic Web, developed by the World Wide Web Consortium (W3C). Protégé is the most popular tool for ontology construction and was developed by Stanford's Medical Informatics Section [5].

Building an ontology with OWL involves the definition of three specific elements: Classes, Properties and Individuals. While the classes and their properties form a model in a machine-understandable format, the individuals correspond to the instances or data described by that model. For each national model, the OWL classes and properties were taken from the corresponding UML model or form 
structure. The instances, however, were taken from the forms content, that is, the cases of study. Finally, a next step is the definition and formalization of a metalanguage to allow the mapping or translation among the different models in order to enable the comparison of curriculums under different national systems.

\section{Conclusions}

This work presents the use of ontologies as a way to tackle the problem of integration of qualification systems not in terms of workload (as credit systems do) but at a semantic level (e.g. content and competence contrast). The qualification systems of nine EU countries have been considered, all of them at the post-secondary non-academic level (VET). Key elements have been the use of UML as a visual aid for the models, and template forms to ensure the understanding of the models and their correctness.

The formalized models allow a clear and unambiguous understanding of the qualification systems analyzed, enabling mutual understanding and the comparison of the elements of such systems. Concrete qualification profiles have been used as study cases to check the correctness of each of the obtained models.

\section{Acknowledgement}

The work is part of tHe European Learning Network - H.E.Le.N. Project [3] funded by the Leonardo da Vinci Programme (LdV Pn IT/04/B/F/NT-154056) under the European Commission.

\section{References}

1. European Commission, "The Copenhagen Declaration", November, 2002. Available online at: europa.eu.int/comm/education/copenhagen/copenahagen_declaration_en.pdf

2. Fensel, D. "Ontologies: A Silver Bullet for Knowledge Management and Electronic Commerce". Springer, Berlin, 2004.

3. H.E.LE.N. Consortium, "DOMAINS Collection". 2005. At: http://www.helen.polito.it

4. Unified Modeling Language (UML) Available online at: http://www.uml.org

5. Protégé Ontology Tool. Available at http://protege.stanford.edu/download/release/full/

6. European Commission, "ECTS - European Credit Transfer and Accumulation System". At http://europa.eu.int/comm/education/programmes/socrates/ects/index_en.html

7. European Convention on the Academic Recognition of University Qualifications (ETS No. 032). At: http://www-ilo-irror.cornell.edu/public/english/employment/ skills/recomm/instr/coe_3.htm

8. European Commission, "European Credit System for VET(ECVET) -Technical Specifications". lecvt2005_en.pdf 